\title{
A PROGRAM FOR THE TRANSFER OF MANUFACTURING TECHNOLOGY FROM THE NATIONAL L,ABORATORIES
}

Annual Performance Report

DE92 011905

for Period March 12, 1990 - March 11, 1991

R. H. Shackson

Industrial Technology Institute

P.O. Box 1485

Ann Arbor, MI 48189

March 1992

APR 201992

Prepared for

THE U.S. DEPARTMENT OF ENERGY

AGREEMENT NO. DE-FG02-90ER75564

\section{NOTICE}

This report was prepared as an account of work sponsored by the United States Government. Neither the United States nor the Department of Energy, nor any of their employees, nor any of their contractors, subcontractors, or their employees, makes any warranty, express or implied, or assumes any legal liability or responsibility for the accuracy, completeness, or usefulness of any information, apparatus, product or process disclosed or represents that its use would not infringe privately owned rights. 


\begin{abstract}
The objective of this project is to test a needs-driven approach to transfer of manufacturing technology from the National Laboratories. The first task was the development of a 250-page book, describing the durable goods industry and its technological needs. This book was used in three engagements with DOE labs, in which researchers were briefed on needs, and asked to nominate technologies to meet these needs. Of 47 nominations, approximately one-third were technologies that had not been recognized as having value, and were not listed on the Laboratory's data base. After several evaluation steps, commercialization planning is underway for six, and one is being considered for prototype development.
\end{abstract}

\title{
Progress
}

Progress with the five tasks of this project is described below.

\section{TASK I: Identify Technology Opportunity Niches}

In a 250-page manual, ITI researchers have consolidated four years of research relative to the technical reeds of durable goods manufacturers ${ }^{1}$ This research included more than a dozen large-sample surveys of technology adoption and inplementation, development needs and benelits analysis; and collection of substantial qualitative data on emerging technology needs of manufacturing. This information has been organized by industry, which subsections describing industry demographics, the level of technology used, research intensity and innovativeness, trends in output and demand, trends in government regulations, and future trends and directions in the production processes for each industry. The manual includes a second section that focuses on manufacturing functions and issues (product/process design, control and monitoring, communications/information management, materials, materials handling), and a third section describes discrete manufacturing processes. An annotated bibliography is included.

These manuals are shipped to the labs for review prior to the ITI site visit.

\footnotetext{
${ }^{1}$ Industries included are: lumber and wood products, furniture and fixtures, rubber and plastics; stone, clay and glass products; primary metals; fabricated metal products; industrial machinery and equipment; electronic and other electrical equipment; and transportation equipment.
} 


\section{TASK II: Search for Technology Matches}

Six-member technical field teams have conducted two-day seminars at Argonne National Laboratory in Illinois, Pacific Northwest Laboratory in Washington and EG \& G Mound Laboratories in Ohio. These seminars have included an orientation by lab management about their operations and technologies, and a tour of lab facilities. ITI researchers have conducted two hour briefings to an audience of senior lab researchers relative to the manufacturing technology, process and functions of industries deemed most appropriate to the technoiogies developed at each lab.

On day two of the engagement, ITI has facilitated a technology brainstorming and discussion session with lab researchers, identifying and discussing technologies with potential manufacturing application. Lab researchers complete four-page Technology Nomination Forms, providing preliminary information about a nominated technology and its potential application, features, state of development, market, protertion, etc. These Nomination Forms form the basis of one-on-one interviews between ITI researchers and the technology inventor, to clarify any issues raised in the forms.

Twenty technology nominations have been uncovered at Argonne, thirteen from PNL, and fourteen from Mound. Approximately one-third of these previously had not been recognized to have commercialization potential; ITI has identified new applications for others.

\section{TASK III: Technology Evaluation and Selection}

Each of the nominated technologies from Argonne and PNL has been evaluated and rated, individually and collectively, by teams of technical experts relative to its potential application, current status of development, novelty, appropriateness, potential market size, degree of technical risk, and availability of a champion. The evaluation process is just getting underway for the Mound technologies, which were submitted in late February.

Three Argome technologies and three PNL technologies were selected for development of detailed commercialization plans.

\section{TASK IV: Development of Commercialization Strategy for Selected Technologies}

Commercialization plans for selected lab technologics are the result of extensive research into the following areas:

1. Background: A problem statement is drafted, identifying the need to be met 
by the type of technology under consideration. Research is performed relative to the state-of-the-art of the technologies currently in use.

2. The Technology: A detailed description of the lab technology is documented. Research is conducted relative to the technology's potential application, its apparent novelty, advantages and disadvantages.

3. Market: Market research is conducted in the following areas:

a. potential market size

b. how the malket, currently is served

c. competitive products and producers

d. competitive price and elasticity

Based on the information uncovered above, the following documents are produced, constituting a commercialization plan:

4. Technical Plan: This step-by-step plan will include a description of the current development status of the technology; the technical objective, i.e., the planned stat of technical development to be achieved; the capabilities the device must meet; key steps and performers in the development process; risks and fallback strategies; and the projected cost and time required to complete development.

5. Marketing Plan: This plan will describe the marketing objective (e.g. license, start-up), key steps and performers, risks and fallback strategies, and projected cost and time involved to market the technology.

6. Intellectual Property Protection: This report will document the status of the existing protection on the technology, and a strategy and plan for protecting the technology further, if appropriate.

7. Financial Proforma: 'This document will estimate the financial return on the marketed technology over a five-year period.

Following is a listing of the technologies selected for development of commercialization plans, and the current status of those plans.

Argonne Technologies

1. Ultrasonic Viscometer: This instrument measures licquid viscosity. The unique features of the device are its in-process and non-intrusive capabilities. 
Identified potential ratuser industries are chemicals, plastics, paint, adhesives and sealants, lubricating fluids, surface active agents, printing ink, fibers, meat products and canned foods.

Plans to develop a prototype of the technology are underway, beginning with a feasibility study. This development will represent the implementation phase of the project, TASK V.

2. Ultrasonic Surface Texture Device: This instrument is used to inspect surface condition, in-process.

Prior art supplemented by additional information provided by the inventor, resulted in a determination that a proprietary position could not be established for this technology. Therefore, commercialization efforts have been discontinued.

3. Ion Beam Assisted Deposition (IBAD) of Lubricious Wear-Resistant Coatings: This process provides highly adherent coatings of solid lubricants on various ceramic and metal substrate.

Market research determined that this technology represents an established process, but there may be novelty in the coatings, themselves. Research is continung to determine whether the silver and boric acid coatings have market potential. If so, ITI will attempt to identify a commercial partner.

\section{Pacific Northwest Technologies}

1. Foam Lumber: This cost-effective process-technology will produce extruded foamed shapes from scrap plastics. The results are durable, attractive, uniform and "nail-able." Our market research disclosed a number of competitive products already on the market. The foaming technique, thought to be proprietary, was also found to be in use. This technology was therefore eliminated.

2. Graphite Reinforced Plastic Nuts and Bolts: This process for molding plastic parts can insure that the fiber reinforcement extends into the teeth of bolts, resulting in a thread with the strength of the body. Unfortunately, the strength was found to be significantly less than for competitive nonferrous metals, resulting in a very limited market potential.

3. Aluminum Electrode: This replacement technology for carbon anodes has low degradation and long life. Developed originally for the aluminum industry, the technology was not economically competitive. Our market research indicated that it could find application in welding and cutting. Samples have been requested, and field tests are planned. 
Plan

We have requested and received a nowcost extension ol this project to allow time for development of the prototype Viscometer based on an Argontie technology, and to complete evaluation and compuercialization planning of technologies nominated at, Mound in February, 1901. 
